\title{
Desenvolvimento e aceitabilidade de geléia dietética de cubiu (Solanum sessiliflorum Dunal)
}

\author{
Development and acceptability of a low calorie cubiu (Solanum sessiliflorum Dunal) jam
}

\author{
Lucia Kiyoko Ozaki YUYAMA ${ }^{1 *}$, Lílian PANTOJA ${ }^{1}$, Roberto Nobuyuki MAEDA ${ }^{1}$, \\ Jaime Paiva Lopes AGUIAR ${ }^{1}$, Socorro Barreto da SILVA ${ }^{1}$
}

\begin{abstract}
Resumo
Visando o aproveitamento de frutos amazônicos e atender à demanda crescente por novos produtos no mercado, foi formulada e avaliada a aceitabilidade e vida-de-prateleira da geléia de cubiu contendo xilitol em substituição à sacarose. Os frutos procedentes da Estação Experimental do Ariaú do Instituto Nacional de Pesquisas da Amazônia foram branqueados, despolpados, triturados, peneirados e acondicionados em embalagens plásticas à temperatura de $-20 \pm 1^{\circ} \mathrm{C}$ até o momento da utilização. Concomitantemente, uma alíquota da polpa foi analisada quanto à umidade, proteínas, lipídios, fibras solúveis e insolúveis, cinza, $\mathrm{pH}$, acidez total, açúcares totais e redutores, e compostos fenólicos. Para a formulação da geléia com uso de xilitol e convencional foi utilizada a proporção de 1:1 (polpa:xilitol e polpa:sacarose), respectivamente. A mistura foi concentrada até a obtenção de $65^{\circ} \mathrm{Brix}$, com ajuste de $\mathrm{pH}$ e adição de pectina. As geléias foram avaliadas quanto aos teores de proteínas, lipídios, cinza, $\mathrm{pH}$, acidez, açúcares e compostos fenólicos e a vida-de-prateleira por meio de análises físico-química, microbiológica e sensorial, mensalmente, por um período de 180 dias. Os resultados demonstraram que não houve diferença estatística entre a aceitabilidade das geléias à base de xilitol e convencional, e que ambas apresentaram estabilidade físico-química e microbiológica durante o seu armazenamento. O xilitol pode ser uma alternativa viável em substituição à sacarose para o preparo de geléia de cubiu.
\end{abstract}

Palavras-chave: cubiu; geléia dietética; xilitol.

\begin{abstract}
With the aim of improving utilization of Amazonian fruits and satisfying the growing demand for new products in the market, we formulated a low calorie cubiu jam with xylitol as a sucrose substitute, and evaluated its shelf life and acceptability. The cubiu fruits from the Experimental Station of the National Research Institute of Amazonia (INPA) were harvested, bleached, pealed, ground, sieved, and stored in plastic bags at $-20 \pm 1{ }^{\circ} \mathrm{C}$ until their utilization. At the same time, triplicate samples of the cubiu pulp were analysed for humidity, protein, lipids, soluble and insoluble fibers, ash, $\mathrm{pH}$, total acidity, total and reducing sugars, and phenolic compounds. The conventional and the xylitol-based jams were prepared with a 1:1 proportion of pulp:sucrose or pulp:xylitol, respectively. The mixture was concentrated up to $65^{\circ}$ Brix with $\mathrm{pH}$ adjustment and pectin addition. The jams were analyzed for protein, lipids, ash, $\mathrm{pH}$, acidity, sugar, and phenolic compounds. The shelf life was evaluated through monthly physicochemical, microbiological, and sensory analyses for a period of 180 days. The results showed no statistical difference between the acceptability of conventional and xylitol-based jams and presented the same physicochemical, microbiological stability during storage. Xylitol can be a viable sucrose substitute for the preparation of cubiu jams.
\end{abstract}

Keywords: cubiu; jam; xylitol.

\section{Introdução}

A região amazônica, detentora da maior biodiversidade, com espécies promissoras como o cubiu (Solanum sessiliflorum Dunal) impõe a necessidade de inovações tecnológicas adequadas à realidade local. Planta tipicamente amazônica, o cubiu (Solanum sessiliflorum Dunal) é um dos recursos genéticos nativos da Amazônia, completamente domesticado pelos povos indígenas da região antes da chegada dos europeus. Nas últimas décadas, este material genético foi muito estudado, sendo os trabalhos científicos mais importantes desenvolvidos na Amazônia brasileira e peruana os de Pahlen (1977), Silva Filho et al. (2005) e o mais completo o manual técnico publicado por Silva Filho (1998).

Sob o ponto de vista econômico, o cubiu tem se constituído em uma importante matéria-prima para a agroindústria moder- na, por reunir atributos como: produtividade, podendo atingir 100 toneladas por hectare de frutos; rusticidade; precocidade; e fácil cultivo (SILVA FILHO, 1998). O fruto é exótico e possui sabor característico e agradável, podendo ser utilizado de múltiplas formas (sucos, doces, geléias, compotas, molhos para temperar carnes de um modo geral, cosméticos e medicamentos caseiros para controlar os altos níveis de colesterol, ácido úrico e diabetes. De sabor típico, ácido, considerável teor de pectina e boas características nutricionais (SILVA FILHO, 2005), o cubiu pode contribuir como valor agregado a produtos, como a geléia, que, apesar de ser um produto disponível no mercado, torna-se uma nova opção de produtos genuinamente regionais para uma parcela da população com restrição a açúcares. Para atender às necessi-

Recebido para publicação em 25/7/2007

Aceito para publicação em 9/4/2008 (002710)

${ }_{1}$ Coordenação de Pesquisas em Ciências da Saúde-CPCS, Instituto Nacional de Pesquisas da Amazônia - INPA, Av. André Araújo, 2936, Aleixo, CEP 69060-001,

Manaus - AM, Brasil, E-mail: yuyama@inpa.gov.br

${ }^{*}$ A quem a correspondência deve ser enviada 
dades desses indivíduos, vários estudos têm sido realizados, com o emprego de edulcorantes. O xilitol, álcool pentahidroxilado, derivado da xilose é considerado um adoçante capaz de substituir a sacarose, podendo ainda, ser utilizado por diabéticos, uma vez que seu metabolismo via pentose fosfato, formando água e $\mathrm{CO}_{2}$ é independente de insulina (MUSSATTO; ROBERTO, 2002). Sua resposta glicêmica é 15 , quando comparado com a sacarose que é de 65. Além disso, possui outras indicações na área clínica no que se refere a desordem no metabolismo de lipídios, disfunção renal, prevenção de otite, infecções pulmonares, osteoporose e propriedade anticariogênica (MÄKINEN, 2000).

O xilitol está presente em produtos que estão disponíveis há mais de 20 anos no mercado da Europa e Escandinávia, sendo naturalmente encontrado em vegetais como uva, morango, alface, cebola e cenoura. Tamanini et al. (2004) reportaram que este produto faz parte do metabolismo intermediário de carboidratos em humanos e animais, sendo produzido industrialmente a partir de fontes celulósicas como casca de árvores.

Yuyama et al. (2005), por meio de estudos preliminares, tendo ratos como modelo experimental, constataram ação hipoglicemiante do cubiu. Portanto, a utilização desse fruto como matéria-prima, para a formulação de geléia dietética e convencional, poderá contribuir não só para o desenvolvimento sócio-econômico da Região Amazônica, como também beneficiar os pacientes com restrição de sacarose.

Sendo assim, o presente estudo teve por objetivo, elaborar geléia de cubiu empregando xilitol em substituição à sacarose e avaliar sua aceitabilidade e vida-de-prateleira.

\section{Material e métodos}

\subsection{Material}

Foram utilizados frutos de cubiu (Solanum sessiliflorum Dunal), de uma única etnovariedade (específica para o processamento de geléia, em função do tamanho), provenientes da Estação Experimental do Ariaú, da Coordenação de Pesquisas em Ciências Agronômicas do Instituto Nacional de Pesquisas da Amazônia (INPA), localizado no Município de IranbudaAM. A pectina e o ácido cítrico foram obtidos no comércio especializado, a sacarose (Itamarati) no comércio local e o xilitol de uma empresa importadora (Tovane).

\subsection{Métodos}

\section{Processamento da matéria-prima}

No Laboratório de Alimentos e Nutrição/CPCS-INPA, os frutos foram selecionados quanto à sanidade, sanitizados com hipoclorito de sódio $(\mathrm{NaOCl})$ 0,2 g.L $\mathrm{L}^{-1}$, seguido de enxágüe, retirada da semente, branqueamento a $90^{\circ} \mathrm{C}$ por 5 minutos, descasque e trituração em liquidificador semi-industrial. A polpa foi peneirada (malha de $0,8 \mathrm{~mm}$ ), acondicionada em sacos plásticos de polietileno de $5 \mathrm{~L}$ e armazenada em freezer a $-20 \pm 1{ }^{\circ} \mathrm{C}$ até o momento do uso. Para o cálculo de rendimento e relação percentual entre polpa e fruto, foi considerado o peso do fruto integral e do mesocarpo com a exclusão das sementes.

\section{Elaboração da geléia}

Para a obtenção das geléias, o $\mathrm{pH}$ da polpa foi corrigido para 3,2 com ácido cítrico e foi adicionado sacarose ou xilitol para as geléias convencional e dietética, respectivamente. Em seguida, a mistura foi concentrada em um tacho inoxidável até $65^{\circ} \mathrm{Brix}$ e, então, adicionada de pectina, resfriada até uma temperatura de aproximadamente $60^{\circ} \mathrm{C}$, envasada ainda quente em frascos de vidro com capacidade para $40 \mathrm{~g}$ e armazenada à temperatura ambiente $\left( \pm 25^{\circ} \mathrm{C}\right)$. Na Figura 1, encontra-se o fluxograma com as etapas de elaboração das geléias.

\section{Análises físico-químicas}

A polpa do fruto e a geléia foram analisadas, em três repetições, em triplicata, quanto aos teores de umidade, proteínas, lipídios e cinza de acordo com a AOAC (1998); pH por leitura direta em potenciômetro digital; acidez total por titulometria com $\mathrm{NaOH} 0,1 \mathrm{~N}$ utilizando fenolftaleína como

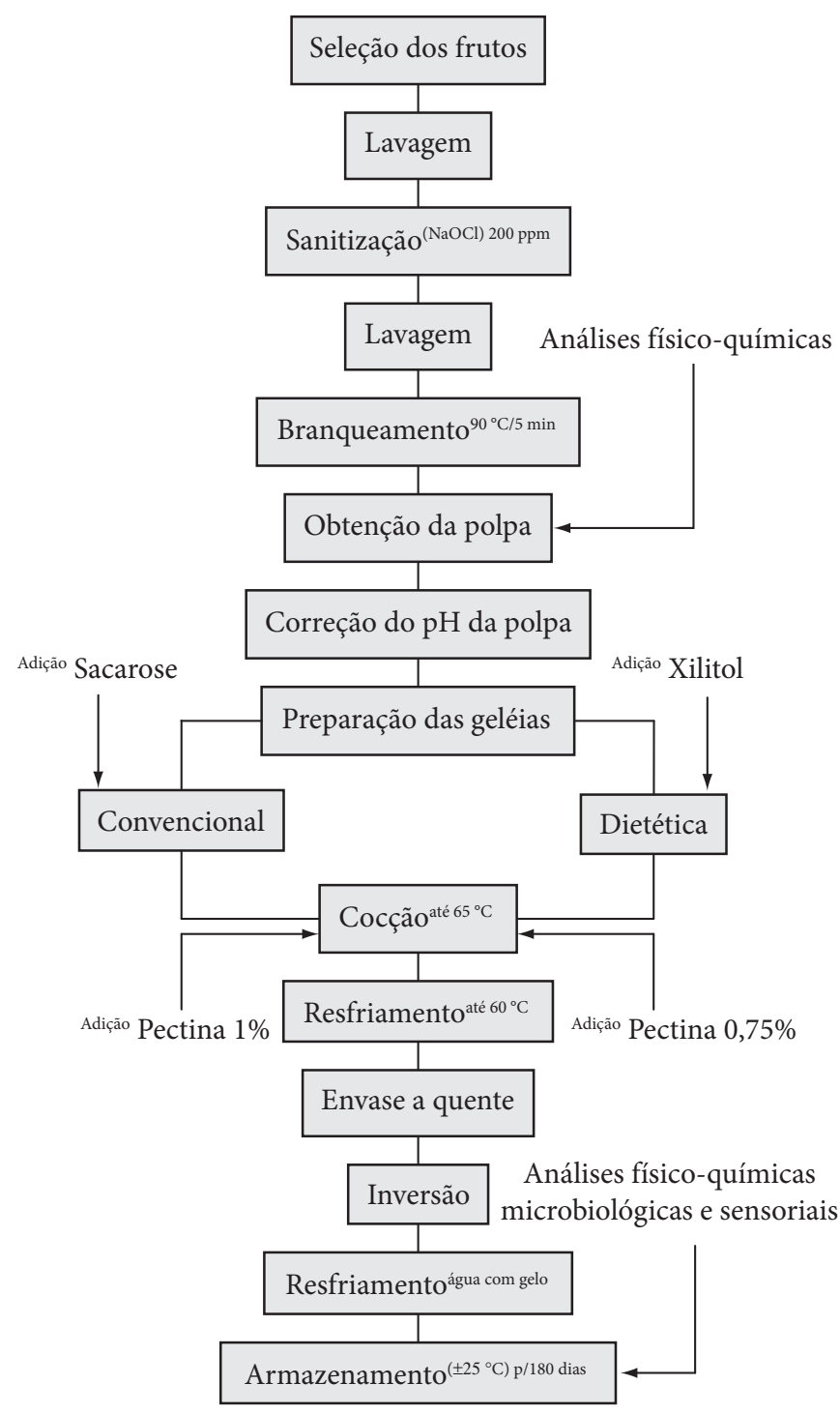

Figura 1. Etapas de elaboração das geléias de cubiu (Solanum sessiliflorum) convencional e dietética. 
indicador segundo IAL-Normas Analíticas do Instituto Adolfo Lutz (1985); açúcares redutores totais (ART) e redutores (AR) de acordo com o método de Somogy-Nelson descrito por Southgate (1991); e compostos fenólicos (CF) segundo Cliff et al. (2008). A fração fibra alimentar foi quantificada pelo método enzímico-gravimétrico de Asp et al. (1983).

Mensalmente, por um período de 180 dias, as geléias foram analisadas quanto ao $\mathrm{pH}$, acidez, açúcares redutores e totais (Instituto Adolfo Lutz, 1985), compostos fenólicos (CLIFFE, 1994), presença de mesófilos, bolores e leveduras, coliformes totais e fecais, e Salmonella sp. de acordo com ICMSF (1988).

Foi avaliada ainda a aceitabilidade da geléia por meio de escala hedônica estruturada de nove pontos de acordo com a metodologia de Monteiro (1984). As amostras foram apresentadas a provadores, não treinados e de forma aleatória, tendo como critério exclusão, pessoas que apresentassem algum indicativo de situação que pudesse mascarar os resultados, tais como fumantes. Os provadores foram os mesmos até o final do experimento, no entanto, destes, apenas 35 foram considerados, uma vez que houve desistências ao longo de 180 dias de avaliação. Foram servidas 6-7 g da amostra em copos descartáveis de $50 \mathrm{~mL}$, codificados com números aleatórios, em temperatura ambiente. Todos os testes foram conduzidos no Laboratório de Alimentos e Nutrição do INPA iluminado com luz fluorescente branca.

\section{Delineamento estatístico}

Os resultados das alterações ocorridas durante o armazenamento foram avaliados pela análise de variância (ANOVA) por meio de delineamento inteiramente casualizado esquematizado em parcelas subdivididas com três repetições, sendo o tratamento principal os diferentes tipos de geléias (com sacarose e com xilitol) e o tratamento secundário, o tempo de armazenamento. A comparação de médias foi por meio do teste de Tukey em nível de 5\% de significância.

\section{Resultados e discussão}

A análise físico-química da polpa de cubiu demonstrou alto teor de umidade, valores ínfimos de proteínas e lipídios e conseqüentemente baixa concentração de energia (Tabela 1), corroborando-a os estudos de Pahlen (1977), Villachica (1996), Maeda e Andrade (1997) e Yuyama et al. (1997; 2005) observaram diferenças na composição química dos frutos de cubiu quando determinaram a composição físico-química de diferentes etnovariedades.

Na Tabela 2, estão apresentados os resultados da composição físico-química da geléia elaborada. Observou-se que os valores da composição das geléias elaboradas com sacarose estão próximos à preparada com xilitol, com exceção dos açúcares totais. Os baixos teores de açúcares detectados na geléia com xilitol, provenientes do fruto, bem como o valor energético fornecido por tal composto, apenas $2,4 \mathrm{kcal} . \mathrm{g}^{-1}$, resultam em um produto com baixo valor energético. Segundo Pereira Jr. (2005), o xilitol é encontrado em processos do metabolismo humano e não há evidências de danos à saúde, o que não se constata em outros tipos de adoçantes artificiais como sacarina, ciclamato e aspartame.

De acordo com as Portarias SVS/MS 27, de 13 de janeiro de 1998 e SVS/MS 29, de 13 de janeiro de 1998 (BRASIL, 2008a; b), o termo Ligth é utilizado para alimentos com valor calórico reduzido ( $25 \%$ do convencional) e o Diet, para os alimentos que são especialmente formulados ou processados, nos quais se introduzem modificações no conteúdo de nutrientes, adequados à utilização em dietas, diferenciadas e/ou opcionais, atendendo às necessidade de pessoas em condições metabólicas e fisiológicas específicas. Dessa forma, as geléias obtidas com o uso de xilitol podem ser designadas de diet e recomendadas aos indivíduos com restrição de açúcares. Quanto ao $\mathrm{pH}$, constatou-se que apesar de a geléia com xilitol apresentar valores próximos do qual formaria uma geléia débil ou mole, a textura obtida foi mais consistente que a elaborada com sacarose, demonstrando assim que o xilitol influenciou positivamente na textura, conferindo maior consistência mesmo em $\mathrm{pH}$ superior $(3,46)$ ao ótimo $(3,2)$ (GAVA, 1998).

Quanto às variáveis avaliadas durante os 180 dias de armazenamento, os resultados estão apresentados nas Figuras 2 e 3 . Constatou-se que, quanto ao $\mathrm{pH}$, houve diferença significativa

Tabela 1. Composição físico-química da polpa de cubiu. Média de três repetições. Valores expressos em $100 \mathrm{~g}$ de matéria integral.

\begin{tabular}{lr}
\hline \multicolumn{1}{c}{ Componentes } & \multicolumn{1}{c}{ Média } \\
\hline Umidade $(\mathrm{g})$ & $94,32 \pm 0,07$ \\
Proteína $(\mathrm{g})$ & $0,033 \pm 0,00$ \\
Lipídios $(\mathrm{g})$ & $0,60 \pm 0,00$ \\
Fibra solúvel $(\mathrm{g})$ & $0,74 \pm 0,00$ \\
Fibra insolúvel $(\mathrm{g})$ & $1,48 \pm 0,00$ \\
Fibra alimentar $(\mathrm{g})$ & $2,22 \pm 0,00$ \\
Cinza $(\mathrm{g})$ & $0,02 \pm 0,00$ \\
Glicídios $(\mathrm{g})$ & $3,41 \pm 0,00$ \\
Açúcares redutores $(\mathrm{g})$ & $1,84 \pm 0,12$ \\
Açúcares totais $(\mathrm{g})$ & $2,15 \pm 0,07$ \\
pH & $4,79 \pm 0,01$ \\
Acidez total $(\mathrm{g})$ & $0,53 \pm 0,01$ \\
Compostos fenólicos $(\mathrm{mg})$ & $189,74 \pm 10,42$ \\
Valor energético (kcal) & 19,16 \\
\hline
\end{tabular}

Tabela 2. Composição físico-química da geléia de cubiu. Valores expressos em $100 \mathrm{~g}$ de matéria integral.

\begin{tabular}{lcc}
\hline \multicolumn{1}{c}{ Componentes } & \multicolumn{2}{c}{ Geléias } \\
\cline { 2 - 3 } & $30,96 \pm 1,40^{\mathrm{a}}$ & \multicolumn{2}{c}{ Sacarose } \\
\hline Umidade (g) & $0,34 \pm 0,02^{\mathrm{b}}$ & $0,38 \pm 0,68^{\mathrm{a}}$ \\
Lipídios (g) & $0,28 \pm 0,002^{\mathrm{a}}$ & $0,22 \pm 0,01^{\mathrm{b}}$ \\
Cinza (g) & $1,54 \pm 0,04^{\mathrm{b}}$ & $67,15 \pm 0,04^{\mathrm{a}}$ \\
Açúcares totais (g) & $3,46 \pm 0,01^{\mathrm{a}}$ & $3,34 \pm 0,01^{\mathrm{b}}$ \\
$\mathrm{pH}$ & $0,89 \pm 0,02^{\mathrm{a}}$ & $0,86 \pm 0,02^{\mathrm{a}}$ \\
Acidez total (g) & $277,68 \pm 12,01^{\mathrm{a}}$ & $235,69 \pm 14,46^{\mathrm{b}}$ \\
Compostos fenólicos (mg) & 272,02 \\
\hline Valor energético (kcal) & 9,32 & \\
\hline
\end{tabular}

Letras iguais dentro da linha, não há diferença estatística em nível de $5 \%$ de significância pelo teste de Tukey. 
( $\mathrm{p} \leq 0,05)$ entre as geléias com xilitol (Figura 2) e a convencional (Figura 3), sendo o maior valor observado na elaborada com xilitol, durante todo o armazenamento. Verificou-se ainda que não houve interação significativa entre os tratamentos principais e secundários, ou seja, o pH não foi influenciado pelo tempo, e o comportamento em ambas as geléias foi o mesmo durante os 180 dias.

Em relação à acidez, não houve diferença significativa entre os tratamentos, e assim uma redução significativa da acidez ao final de 180 dias de avaliação. Entretanto, esta redução pareceu não interferir no sabor do produto, uma vez que não houve comentários negativos durante a degustação.

Os valores de açúcares redutores da geléia elaborada com xilitol apresentaram-se estáveis durante todo o período de armazenamento. Por outro lado, verificou-se um aumento destes açúcares na geléia com sacarose, sugerindo ter ocorrido hidrólise da sacarose durante o período de armazenamento, o que, conseqüentemente, levou à formação de glicídios redutores. Esta hidrólise pode ser atribuída a reações químicas ocasionadas pela presença de ácidos orgânicos, uma vez que açúcares não-redutores como a sacarose é hidrolisada em meio ácido. Ressalta-se que a hidrólise não teve influência na textura, cor, sabor ou aroma das geléias e ainda, como esperado, constatou-se uma interação significativa entre os tratamentos, 0 que demonstra ter havido comportamento diferente durante o armazenamento. A hidrólise de glicídios não redutores durante o armazenamento de produtos processados foi constatada por Maeda (2002) avaliando néctar de camu-camu adoçado com sacarose e armazenado em temperatura ambiente.

Quanto aos açúcares redutores totais, verificou-se uma baixa concentração nas geléias com xilitol, uma vez que este é poliálcool não redutor. $\mathrm{O}$ efeito isolado do tempo não foi
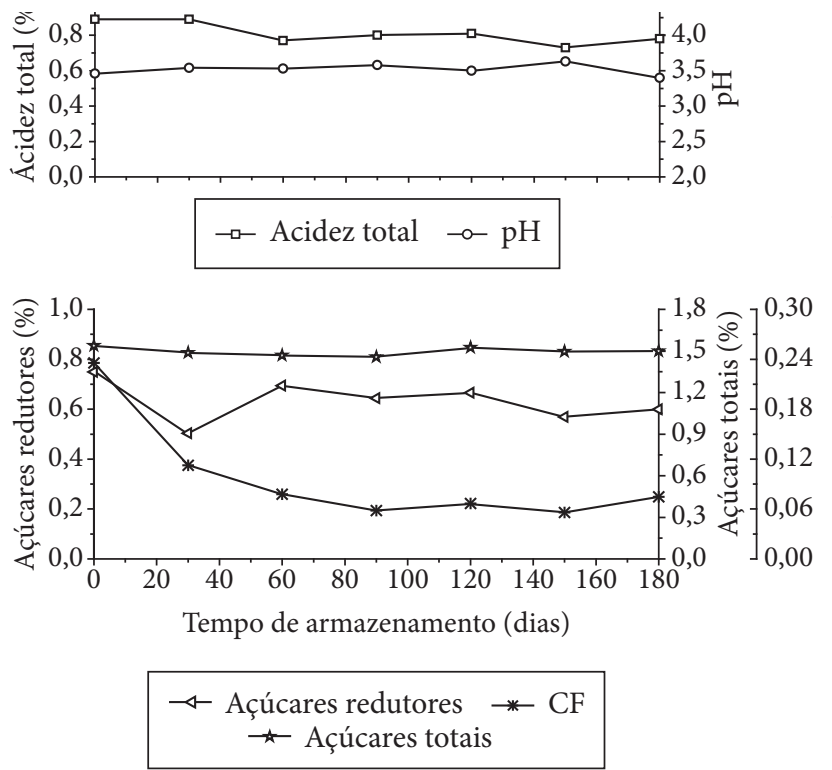

Figura 2. Variáveis físico-químicas da geléia dietética (xilitol) de cubiu durante os 180 dias de armazenamento em temperatura ambiente $\left(24 \pm 1{ }^{\circ} \mathrm{C}\right)$. significativo, entretanto, assim como nos açúcares redutores, houve interação significativa entre os tratamentos principais e secundários durante o armazenamento. Constatou-se ainda uma pequena redução destes a partir de 120 dias de armazenamento nas geléias obtidas com adição de sacarose. Esta redução não foi verificada na geléia dietética, cujos açúcares redutores totais (ART) e redutores (AR) mantiveram-se estáveis durante o armazenamento. Sugere-se que a redução de açúcares neste período tenha sido decorrente do início da reação de Maillard, processo químico em que os açúcares se complexam com aminoácidos formando pigmentos escuros (BOBBIO; BOBBIO, 1992).

Em relação aos compostos fenólicos, constatou-se redução significativa nos primeiros 60 dias de armazenamento, permanecendo constantes após este período. Apesar de os compostos fenólicos estarem diretamente relacionados às características organolépticas de um determinado produto, esta redução, não influenciou na aceitabilidade das geléias, considerando que os provadores não detectaram alterações no sabor, cor ou aroma das geléias.

As geléias de cubiu apresentaram-se com coloração amarelada, sabor e aroma característico do fruto e textura firme, própria de geléia.

A aceitação global foi de 97,06\% para ambas as geléias, com rejeição de apenas 2,94\% e aceitabilidade de $85,62 \%$ para a geléia com xilitol e $81,05 \%$ para geléia com sacarose (Tabela 3 e Figura 4). Por meio da análise estatística, verificou-se que não houve diferença significativa em nível de $5 \%$ de significância, confirmando dessa forma, a similaridade entre as geléias com xilitol e com sacarose.
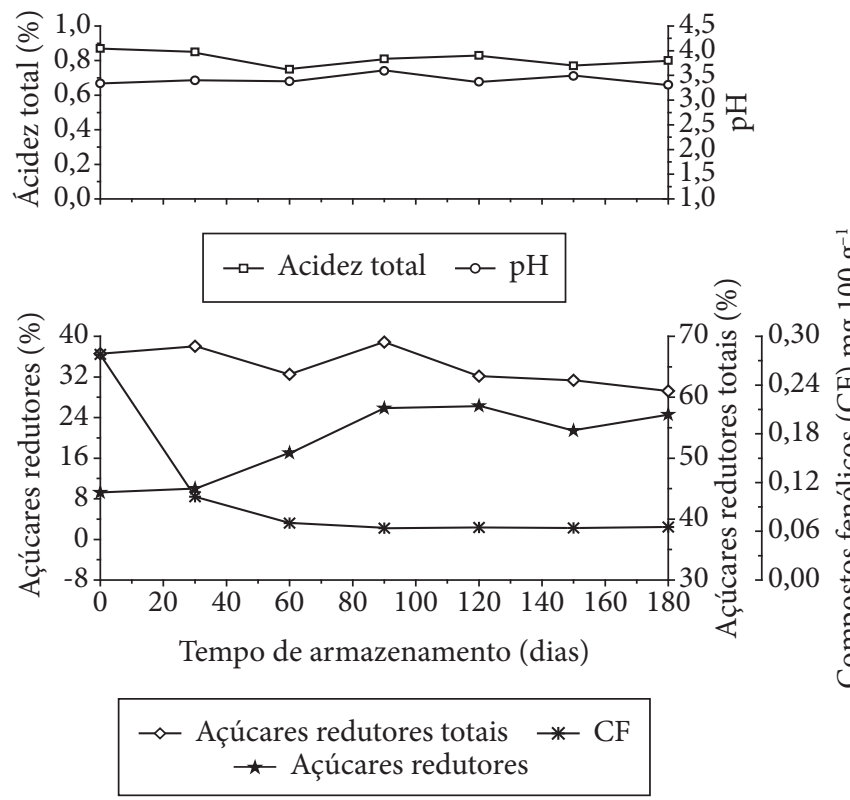

Figura 3. Variáveis físico-químicas da geléia convencional (sacarose) de cubiu durante os 180 dias de armazenamento em temperatura ambiente $\left(24 \pm 1^{\circ} \mathrm{C}\right)$. 
A boa aceitabilidade da geléia dietética de cubiu está no fato de que mesmo usando o xilitol em substituição ao açúcar, esta apresenta sabor semelhante à convencional, com a vantagem de ser hipocalórica (Tabela 2).

Convém destacar que, quanto ao aspecto microbiológico, os resultados obtidos indicaram não haver contaminação durante os seis meses de armazenamento (Tabela 4), sinalizando o emprego das boas práticas de higiene durante o processamento das geléias.

Tabela 3. Notas atribuídas às geléias de cubiu e freqüência de resposta em uma avaliação sensorial por meio de escala hedônica.

\begin{tabular}{lccc}
\hline \multicolumn{1}{c}{ Tratamentos } & Notas & \multicolumn{2}{c}{ Freqüência de respostas (\%) } \\
\cline { 3 - 4 } & (Média \pm DP) & Valores $\leq 4$ & Valores $\geq 6$ \\
\hline Geléia com sacarose & $7,29 \pm 1,00 \mathrm{~ns}$ & 2,94 & 97,06 \\
Geléia com xilitol & $7,71 \pm 1,38 \mathrm{~ns}$ & 2,94 & 97,06 \\
\hline \multicolumn{2}{l}{$\begin{array}{l}\text { ns = diferença não significativa em nível de } \\
\text { sacarose e com xilitol. }\end{array}$}
\end{tabular}

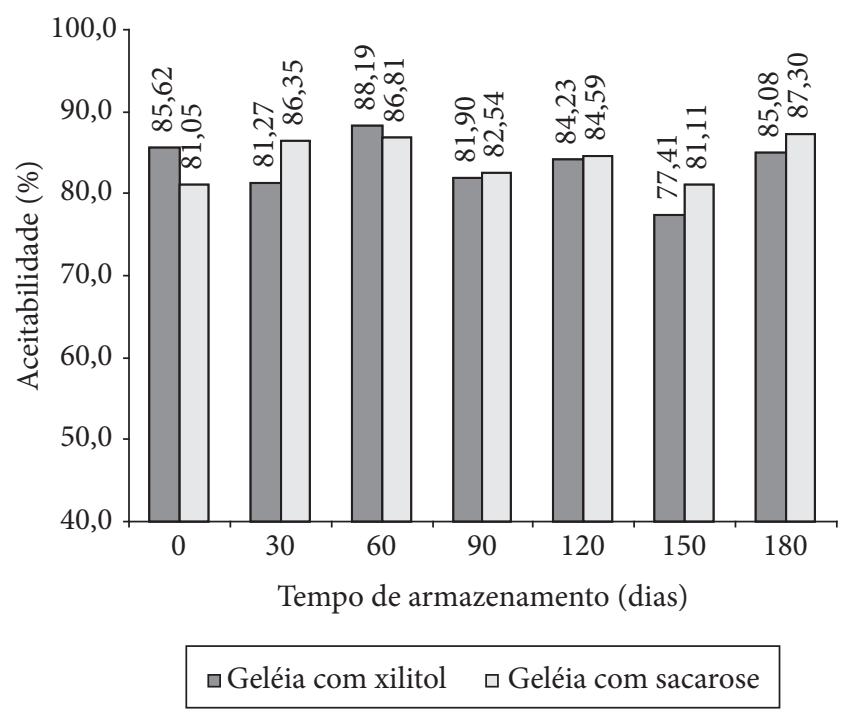

Figura 4. Aceitabilidade das geléias de cubiu no período de 180 dias de armazenamento.

\section{Conclusões}

O uso de xilitol no desenvolvimento da geléia de cubiu mostrou-se satisfatório por resultar em um produto de baixo teor energético, com características próprias de geléia e similar à convencional quanto ao aspecto físico e sensorial, o que permite sugerir sua indicação não só para diabéticos, mas também para indivíduos com necessidade de restrição calórica.

\section{Agradecimentos}

Ao INPA pelo suporte logístico, ao CNPq pelo apoio financeiro (proc. 476293/03-0 ) e pela concessão da bolsa de produtividade (proc. 302811/2003-6), ao Dr. Danilo F. Silva-Filho pelo fornecimento do fruto.

\section{Referências bibliográficas}

ASP, N. G. et al. Rapid enzymatic assay of insoluble and soluble dietary fiber. Jornal Agricultural Food Chemistry, v. 31, p. 476-482, 1983.

AOAC - Association of Official Analytical Chemists. Official methods of analysis. 16 ed. Washington, v. 1, 1998.

BOBBIO, P. A.; BOBBIO, F. O. Química do processamento de alimentos. São Paulo: Varela, 1992. 143 p.

BRASIL. AGENCIA NACIONAL DE VIGILÂNCIA SANITÁRIA (ANVISA). Portaria SVS/MS 27, de 13 de janeiro de 1998. Disponível em: <http://e-legis.anvisa.gov.br/leisref/public/show Act.php?id=97> Acesso em: janeiro de 2008a.

BRASIL. AGENCIA NACIONAL DE VIGILÂNCIA SANITÁRIA (ANVISA). Portaria SVS/MS 29, de 13 de janeiro de 1998. Disponível em: < http://e-legis.anvisa.gov.br/leisref/public/show Act.php?id=17213\&word=> Acesso em: janeiro de 2008b.

CLIFFE, S. et al. Enzymes assays for the phenolic content of natural juices. Jornal Agricultural Food Chemistry, v. 42, p. 1824-1828, 1994.

GAVA, A. J. Princípios de tecnologia de alimentos. 1 ed. São Paulo: Nobel, 1998. 104 p.

INTERNATIONAL COMMISSION ON MICROBIOLOGICAL SPECIFICATIONS FOR FOODS (ICMSF). Microorganisms in foods 4. Applications of the hazard analysis critical control point

Tabela 4. Avaliação microbiológica das geléias dietética e convencional de cubiu.

\begin{tabular}{|c|c|c|c|c|c|c|}
\hline \multirow{2}{*}{$\begin{array}{c}\text { Tempo de } \\
\text { armazenamento (dias) }\end{array}$} & \multirow[t]{2}{*}{ Tipo de geléia } & \multicolumn{5}{|c|}{ Microrganismos } \\
\hline & & $\begin{array}{l}\text { Coliformes totais } \\
\left(\text { NMP.g }^{-1}\right)\end{array}$ & $\begin{array}{l}\text { Coliformes fecais } \\
\left(\text { NMP.g }^{-1}\right)\end{array}$ & $\begin{array}{l}\text { Mesófilos } \\
\left(\text { UFC.g }{ }^{-1}\right)\end{array}$ & $\begin{array}{c}\text { Bolores e leveduras } \\
\left.\text { (UFC. } \mathrm{mL}^{-1}\right)\end{array}$ & $\begin{array}{l}\text { Salmonella sp. } \\
(\mathrm{em} 25 \mathrm{~g})\end{array}$ \\
\hline 0 & Dietética & 0 & 0 & $>10$ & $>10$ & Ausente \\
\hline \multirow[t]{2}{*}{30} & Dietética & 0 & 0 & $>10$ & $>10$ & Ausente \\
\hline & Convencional & 0 & 0 & $>10$ & $>10$ & Ausente \\
\hline \multirow[t]{2}{*}{90} & Dietética & 0 & 0 & $>10$ & $>10$ & Ausente \\
\hline & Convencional & 0 & 0 & $>10$ & $>10$ & Ausente \\
\hline \multirow[t]{2}{*}{120} & Dietética & 0 & 0 & $>10$ & $>10$ & Ausente \\
\hline & Convencional & 0 & 0 & $>10$ & $>10$ & Ausente \\
\hline 150 & Dietética & 0 & 0 & $>10$ & $>10$ & Ausente \\
\hline
\end{tabular}


(HACCP) system to ensure microbiological safety and quality. Oxford: Blackwell Science, 1988.

INSTITUTO ADOLFO LUTZ (IAL). Normas analíticas do Instituto Adolfo Lutz: métodos químicos e físicos para análise de alimentos. São Paulo: EPU, 1985. 533p.

MAEDA, R. N.; ANDRADE, J. S. Fisiologia pós-colheita do cubiu (Solanum sessiliflorum Dunal): aspectos bioquímicos do escurecimento pela ação da peroxidase. In: JORNADA DE INICIAÇÃO CIENTÍFICA DO INPA, 6, 1997, Manaus. Anais... Manaus, AM: INPA, 1997, p. 201-204.

MAEDA, R. N. Estabilidade de ácido ascórbico e pigmentos presentes no néctar de camu-camu (Myrciaria dubia (H. B. K.) McVaugh) armazenados em diferentes condições de luminosidade e temperatura. Manaus, 2002. 98 f. Dissertação - (Mestrado em Ciência de Alimentos), Universidade Federal do Amazonas.

MÄKINEN, K. K. Can the pentitol-hexitol theory explain the clinical observations made with xylitol? Medical Hypothese, v. 54, p. 603-613, 2000.

MONTEIRO, C. L. B. Técnicas de avaliação sensorial. 2 ed. Curitiba: CEPPA, 1984. 101p. mussatto, s. i.; roberto, i. c. Produção biotecnológica de xilitol a partir da palha de arroz. Biotecologia Ciência \& Desenvolvimento, n. 28, p. 34-39, 2002.

PAHLEN, A. V. D. Cocona (Solanum topiro Humbl. \& Bonpl.), un fruto del Amazonas. La cosecha Amazónica, v. 7, p. 301-307, 1977.
PEREIRA JUNIOR, N. UFRJ testa adoçante do futuro. Núcleo de Difusão Científica e Tecnológica. Rio de Janeiro: FAPERJ. Disponível em: http://www.faperj.br/internaphtml?obj_id=167 Acess oem: agosto de 2005.

SILVA FILHO, D. F. Cocona (Solanum sessiliflorum Dunal): Cultivo y utilizacion.. 2 ed. Caracas: Secretaria Pro-Tempore, 1998. v. 1, 114 p.

SILVA FILHO, D. F. et al. Caracterização e avaliação do potencial agronômico e nutricional de etnovariedades de cubiu (Solanum sessiliflorum Dunal) da Amazônia. Acta Amazônica, v. 35, n. 4, p. 399-406. 2005.

SOUTHGATE, D. A. T. Determination of food carbohydrates. London: Ed. Applied Science Publishers LTD, 1991. 177 p.

TAMANINI, C. et al. Avaliação da casca de aveia para produção biotecnológica de xilitol. Acta Scientiarum Technology, v. 26, n. 2, p. 117-125, 2004.

VILLACHICA, H. Cocona (Solanum sessiliflorum Dunal). In: Villachica, H. Frutales y hortalizas promisorios del Amazonas. Lima: Secretaria Pro-Tempore, 1996. p. 98-102.

YUYAMA, L. K. O. et al. Composição centesimal de diversas populações de cubiu (Solanum sessiliflorum Dunal) da Estação Experimental do Instituto Nacional de Pesquisas da Amazônia, INPA. In: Simpósio Latino Americano de Ciência de Alimentos, 2, 1997, Campinas. Anais... Campinas-SP: SBCTA, 1997.

YUYAMA, L. K. O. et al. Estudo da influência do cubiu (Solanum sessiliflorum Dunal) sobre a concentração sérica de glicose. Revista Instituto Adolfo Lutz, v. 64, n. 2, p. 232-236, 2005. 